\title{
Hydrocortisone Valerate
}

National Cancer Institute

\section{Source}

National Cancer Institute. Hydrocortisone Valerate. NCI Thesaurus. Code C48024.

The valerate salt form of hydrocortisone, a synthetic glucocorticoid receptor agonist with antiinflammatory, antipruritic and vasoconstrictive effects. Binding and activation of the glucocorticoid receptor results in the activation of lipocortin that in turn inhibits cytosolic phospholipase A2. Lack of phospholipase A2 prevents the release of arachidonic acid, precursor for inflammatory mediator prostaglandins and leukotrienes, from the cell membrane. Secondly, mitogen-activated protein kinase (MAPK) phosphatase 1 is induced, thereby leads to dephosphorylation and inactivation of Jun Nterminal kinase directly inhibiting c-Jun mediated transcription. Finally, transcriptional activity of nuclear factor (NF)-kappa-B is blocked, thereby inhibits the transcription of cyclooxygenase 2 , which is essential for prostaglandin production. 